\title{
First insights into the molecular basis association between promoter polymorphisms of the ILIB gene and Helicobacter pylori infection in the Sudanese population: computational approach
}

Abeer Babiker Idris ${ }^{1 *} \mathbb{D}$, Einas Babiker Idris ${ }^{2+}$, Amany Eltayib Ataelmanan ${ }^{3 \dagger}$, Ali Elbagir Ali Mohamed ${ }^{4}$,

Bashir M. Osman Arbab ${ }^{5}$, El-Amin Mohamed Ibrahim ${ }^{1}$ and Mohamed A. Hassan ${ }^{6,7,8}$

\begin{abstract}
Background: Helicobacter pylori (H. pylori) infects nearly half of the world's population with a variation in incidence among different geographic regions. Genetic variants in the promoter regions of the $I L 1 B$ gene can affect cytokine expression and creates a condition of hypoacidity which favors the survival and colonization of $\mathrm{H}$. pylori. Therefore, the aim of this study was to characterize the polymorphic sites in the $5^{\prime}$ - region [-687_+ 297] of ILIB in H. pylori infection using in silico tools.

Results: A total of five nucleotide variations were detected in the 5'-regulatory region [-687_+ 297] of IL1B which led to the addition or alteration of transcription factor binding sites (TFBSs) or composite regulatory elements (CEs). Genotyping of $I L 1 B-31 C>T$ revealed a significant association between $-31 \mathrm{~T}$ and susceptibility to $\mathrm{H}$. pylori infection in the studied population $(P=0.0363)$. Comparative analysis showed conservation rates of IL $1 B$ upstream $\left[-368 \_+10\right]$ region above $70 \%$ in chimpanzee, rhesus monkey, a domesticated dog, cow and rat.

Conclusions: In H. pylori-infected patients, three detected SNPs (-338, -155 and -31$)$ located in the ILIB promoter were predicted to alter TFBSs and CE, which might affect the gene expression. These in silico predictions provide insight for further experimental in vitro and in vivo studies of the regulation of $I L 1 B$ expression and its relationship to $\mathrm{H}$. pylori infection. However, the recognition of regulatory motifs by computer algorithms is fundamental for understanding gene expression patterns.
\end{abstract}

Keywords: H. pylori, IL1B, 5'- region, In silico analysis, Sudan

\footnotetext{
* Correspondence: abeer.babiker89@gmail.com

†Einas Babiker Idris and Amany Eltayib Ataelmanan contributed equally to this work.

'Department of Medical Microbiology, Faculty of Medical Laboratory Sciences, University of Khartoum, Khartoum, Sudan

Full list of author information is available at the end of the article
}

(c) The Author(s). 2021 Open Access This article is licensed under a Creative Commons Attribution 4.0 International License, which permits use, sharing, adaptation, distribution and reproduction in any medium or format, as long as you give appropriate credit to the original author(s) and the source, provide a link to the Creative Commons licence, and indicate if changes were made. The images or other third party material in this article are included in the article's Creative Commons licence, unless indicated otherwise in a credit line to the material. If material is not included in the article's Creative Commons licence and your intended use is not permitted by statutory regulation or exceeds the permitted use, you will need to obtain permission directly from the copyright holder. To view a copy of this licence, visit http://creativecommons.org/licenses/by/4.0/ The Creative Commons Public Domain Dedication waiver (http://creativecommons.org/publicdomain/zero/1.0/) applies to the data made available in this article, unless otherwise stated in a credit line to the data. 


\section{Background}

Helicobacter pylori (H. pylori) is a Gram-negative, spiralshaped and microaerophilic bacterium that infects nearly half of the world's population with a variation in incidence among different geographic regions [1, 2]. Epidemiological studies have indicated that the highest prevalence of $H$. pylori was found in Africa (79.1\%), and the lowest prevalence was found in Northern America (37.1\%) and Oceania (24.4\%) with an overall global $H$. pylori prevalence of $44.3 \%$, ranging from $50.8 \%$ in developing countries to $34.7 \%$ in developed countries [3-6]. The global annual recurrence rate of $H$. pylori was (4.3\%) and it was found to be related to the human development index and prevalence of infection [3]. However, the clinical aspects of chronic infection with $H$. pylori vary from gastroduodenal inflammation and peptic ulceration to the most dangerous aspects, gastric carcinoma and mucosa-associated lymphoid tissue (MALT) lymphoma [7, 8]. Also, H. pylori may be implicated in several extra-gastric diseases such as iron deficiency anemia, idiopathic thrombocytopenic purpura, several dermatological disorders, hepatic encephalopathy, diabetes, and pulmonary and cardiovascular diseases [7, 9]. Indeed, the susceptibility to $H$. pylori infection and its diverse clinical presentation is determined by multiple factors, including heterogeneity of $H$. pylori strains and their virulence factors, environmental factors, and the host genetic background, especially those regarding polymorphisms in certain cytokines, gene regulation and their receptor antagonist genes [10-13]. One of these cytokines is the interleukin 1-beta (IL1B) gene.

$I L-1$ family genes, spanning $\sim 430 \mathrm{~kb}$, cluster on chromosome 2q13-21 and consist of $I L-1 A, I L-1 B$, and $I L-1 R N$ genes which encode the pro-inflammatory cytokines IL- $1 \alpha$ and IL-1 $\beta$ and the endogenous receptor antagonist IL-1ra, respectively [14]. IL-1 $\beta$, the crucial cytokine in the gastrointestinal tract [15], has a variety of biological activities on a wide range of tissues and plays an important role in inflammatory, metabolic, physiologic, hematopoietic, and immunological processes (for a review, see references (16) and [17]). Because of the ability of IL-1 $\beta$ to inhibit gastric acid secretion, it may have a profound effect on the natural history of $H$. pylori infection by allowing expansion of $H$. pylori colonization from the gastric antrum to the corpus $[15,18-20]$. On a molar basis, IL-1 $\beta$ is 100 -fold more potent than proton pump inhibitors (PPIs) and 6000-fold more potent than $\mathrm{H} 2$ receptor antagonists [21].

IL-1 $\beta$ is expressed at high levels in myeloid cell lineages in response to tissue injury and microbial invasion $[22,23]$. Also, many different types of cells, e.g. B cells, T cells, NK cells, dendritic cells, fibroblasts and epithelial cells, express this protein in response to a broad range of stimuli and under inflammatory conditions but at much lower level [24-26]. LPS-inducible IL1 $\beta$ expression is regulated by two regions: a proximal promoter that contains a TATA box and an upstream LPSresponsive enhancer (located between - 3757 and 2729), which is also known as the upstream inducible sequence $[27,28]$. In monocyte, this promoter is packaged into a highly accessible chromatin structure which is characterized by the constitutive association of PU.1 and $\mathrm{C} / \mathrm{EBP} \beta$, but the inducible association of RNA polymerase II $[24,29,30]$. The following multiple transcription factors that constitutively and inducibly associate with IL-1 $\beta$ regulatory regions have been identified: Spi-1/ PU.1 (Spi1), NF-kB, C/EBP $\beta$, AP-1, TBP, SSRP, or c-Jun and c-fos [29].

Genetic variations in the promoter region of genes encoding cytokines were shown to correlate with individual differences in the expression of respective cytokines which may influence the intensity of the inflammatory response and susceptibility to many diseases [31-35]. IL$1 B$ gene has two allelic variants (CT; dbSNP: rs16944) and (TC; dbSNP: rs1143627) which are located at positions -511 and -31 , respectively, in the promoter region. These SNPs have been proposed to be associated with the susceptibility to $H$. pylori infection; and $H$. pylori-related gastric cancer and peptic ulcer disease [36], but it is still a contradictory topic of debate. Many studies have been published analyzing the contribution of $I L 1 B$ promoter polymorphisms to $H$. pylori susceptibility with conflicting results explained, in part, by ethnic differences [19, 32, 36]. In the present study, genomic DNA Sanger sequencing was applied to detect SNPs in the region [-687_+ 297] of $I L 1 B$ in $H$. pylori-infected patients; and bioinformatics analyses were used to study whether these mutations would alter transcription factor binding sites (TFBSs). Further computational analysis was also made to investigate other potential regulatory elements in this region. Finally, comparative profiling was conducted to assess the conservation of these genetic variations in 11 species. However, to our knowledge, the association between promoter polymorphisms of the $I L 1 B$ gene and $H$. pylori infection in the Sudanese population has not been studied. It is imaginable that individual differences in $H$. pylori susceptibility or individual differences in $H$. pylori-related disease severity are linked to genetically determined differences in $I L 1 B$ production. Therefore, studying the regulation of $I L 1 B$ gene expression is of great significance.

\section{Results}

Nucleotide variations in the 5'-regulatory region of the IL1B gene

In Sudanese $H$. pylori infected patients, a total of five nucleotide variations were detected in the $5^{\prime}$-regulatory 
region. Among which, three are bimodally mutated heterozygous SNPs, and they were newly discovered; the positions of these three SNPs are $-338,-155$ and +38 . The other two SNPs were rs16944 and rs1143627, see Table 1 for more illustration. The nucleotide sequences of the IL1B 5' - region [-687_+ 297] were deposited in the GenBank database under the following accession numbers: from MT767762 to MT767775.

\section{In silico prediction of the ILIB promoter regions}

Five types of promoter prediction programs were employed to predict the promoter regions of the $I L 1 B$ $5^{\prime}-$ region $[-687+297]$ and the results are presented in Table 2. The Promoter 2.0 Prediction Server predicted no promoter region. Neural Network Promoter Prediction (NNPP version 2.2) predicted three promoter regions, located at $-328 \mathrm{bp},-124 \mathrm{bp}$ and $+1 \mathrm{bp}$ relative to the IL1B translational start codon (transcript NM 000576.3), whose prediction scores were 0.97, 0.60 and 0.96, respectively. While Fprom, TSSG and TSSW programs predicted one promoter region, $+1 \mathrm{bp}$, which is the only region predicted by all used prediction programs.

\section{In silico analysis of predicted ILIB promoter regions}

ENCODE data showed a high level of DNase I hypersensitivity, promoter associated histone modifications and transcription factor occupancy patterns at -124 and +1 bp promoter regions. While no Nuclease hypersensitivity around $-328 \mathrm{bp}$ region. However, no $\mathrm{CpG}$ islands were detected in the predicted promoter regions (Fig. 1). Also, ENCODE data confirmed no presence of the CpG island in the predicted promoters.

Conservancy of the predicted promoter region $[-368+10]$ The ECR Browser revealed mammalian conservation for the $\left[-368 \_+10\right]$ region in chimpanzee (Pan troglodytes - pan-Tro2) (99.2\%), rhesus monkey (Macaca mulatta rheMac2) (93.4\%), domesticated dog (Canis lupus familiaris - canFam2) (73\%), cow (Bos Taurus - bosTau3) (71.1\%), rat (Rattus norvegicus - rn4) (70.5\%) and mouse (Mus musculus - mm9) (69.3\%). But the region was not conserved in opossum (Monodelphis domestica), chicken (Gallus gallus), frog (Xenopus laevis), zebrafish (Danio rerio), fugu pufferfish (Takifugu rubripes), and spotted
Table 2 Overview of the computational predicted ILIB promoter regions for the respective prediction programs. The most predicted region is indicated in bold

\begin{tabular}{|c|c|}
\hline Prediction program & Predicted promoter regions $\mathrm{s}^{\mathrm{a}}$ \\
\hline \multirow[t]{3}{*}{ BDGP (NNPP version 2.2) } & $-368 z_{-}-319$ \\
\hline & $-164_{-}-115$ \\
\hline & $-40_{-}+10$ \\
\hline Fprom & +1 \\
\hline Promoter 2.0 Prediction Server & no promoter \\
\hline TSSG $^{c}$ & +1 \\
\hline TSSW $^{d}$ & +1 \\
\hline
\end{tabular}

${ }^{\mathrm{a}}$ All positions are given in base pairs relative to the translational $/ L-1 B$ start codon (transcript NM_000576.3)

${ }^{b}$ Neural Network Promoter Prediction, Threshold 0.50

${ }^{\circ}$ Threshold for LDF- 4.00

${ }^{\mathrm{d}}$ Thresholds for TATA+ promoters - 0.45, for TATA-/enhancers - 3.70

green pufferfish (Tetraodon nigrovoridis), see Fig. 2 for more illustration.

\section{Prediction of TFBSs}

In this study, five programs were used to predict TFBSs and to insure proper analysis we only selected factors that are predicted by three out of the five programs or the factors predicted by two programs but verified in the literature. The five prediction programs reported multiple putative TFBSs within the $\left[-368_{-}+\right.$ 10] region, see Table 3 and Figs. 3, 4 and 5. However, screening of this region, by using the NCBI SNP databases (dbSNPs), revealed the presence of 9 SNPs upstream of the $I L 1 B$ core promoter region which are shown in Table 4. The ECR Browser and NCBI BLASTn showed the conservation of these SNPs in chimpanzee, rhesus monkey, cow and dog. Mulan revealed multiple TFBSs to be located at rs749558279, rs140623868 and $-338 \mathrm{~A}>\mathrm{T}$. The overview of conserved TFBSs predicted by Mulan to be conserved (100\%) between human, chimpanzee, rhesus monkey, cow and domesticated dog is summarized in Table 4.

\section{Prediction of CEs}

MatrixCatch was used to find known regulatory elements (both single sites and pairs) which were verified experimentally. Also, it found novel regulatory elements by computational comparison but without experimental

Table 1 Nucleotide changes in the 5'-regulatory [-687_+ 297] region of the IL1B gene in $H_{\text {. }}$ pylori-infected patients

\begin{tabular}{lllll}
\hline SNP & Event & SNP Locus & Chromosome Position & Serial Number (rs) \\
\hline T $>$ C (heterozygous) & Transition & +38 & NG_008851.1:g.5039 & - \\
C $>$ T (heterozygous and homozygous) & Transition & -31 & NG_008851.1:g.4970 & rs1143627 \\
G $>$ C (heterozygous) & Transversion & -155 & NG_008851.1:g.4844 & - \\
A $>$ T (heterozygous) & Transversion & -338 & NG_008851.1:g.4666 & - \\
T $>$ C (heterozygous and homozygous) & Transition & -511 & NG_008851.1:g.4490 & rs16944 \\
\hline
\end{tabular}




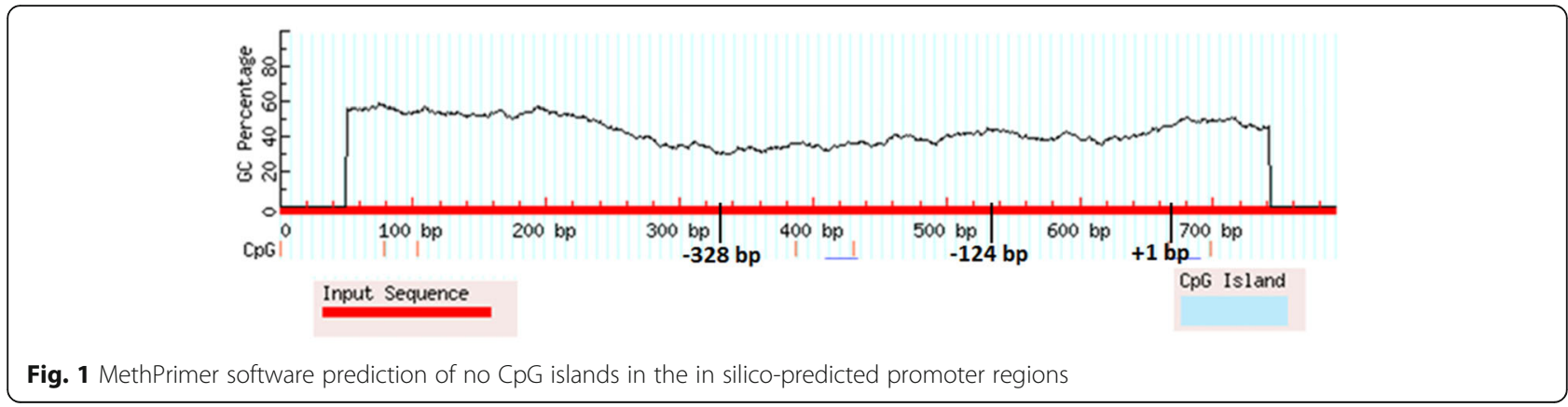

verification on functionality. These elements were found by using similarity to known ones in a library of $\mathrm{CE}$ models [38]. The summary of predicted CEs by MatrixCatch is presented in Table 5 .

\section{Allele and genotype frequencies of IL1B-31 and susceptibility to $H$. pylori infection}

Sixty-one patients and 61 uninfected controls were successfully genotyped for the $I L 1 B-31 \mathrm{C} / \mathrm{T}$ polymorphism (Fig. 4). The frequency of allele $\mathrm{T}$ and $I L 1 B-31 \mathrm{~T} / \mathrm{C}+\mathrm{T} /$ $\mathrm{T}$ genotypes were significantly higher in $\mathrm{H}$. pylori-infected individuals compared to uninfected controls (36.89\% versus $23.77 \%, P=0.0363$ and $54.1 \%$ versus $34.43 \%, P=0.0445$, resp.). The allelic and genotype distributions of $I L 1 B-31 \mathrm{C} / \mathrm{T}$ polymorphism followed those expected in Hardy-Weinberg equilibrium (HWE) for control population $(P=0.1366)$ (Table 6$)$.

\section{Discussion}

Genetic variants in the promoter region of $I L 1 B$ gene can affect cytokine expression and create a condition of hypoacidity which favors the survival and colonization of $H$. pylori $[15,36]$. In the present study, we functionally analyzed SNPs in the IL1B 5'-region [-687_+ 297] of Sudanese patients infected with $H$. pylori and developed divergent clinical outcomes. We observed three novel mutations $(-338,-155$ and +38$)$ and interestingly, two of them (-338 and-155) were located at in silicopredicted promoter regions. Thus, these mutations might play a role in regulating the expression of $I L 1 B$. In this study, the computational analysis predicted three promoter regions at $-328,-124$ and +1 , but two of them $(-328$ and -124$)$ were only predicted by the NNPP algorithm that uses neural networks (NNs). NNs have been applied for promoter prediction since 1991 [39]. The study conducted by Liu and States et al. compared different available prediction techniques during

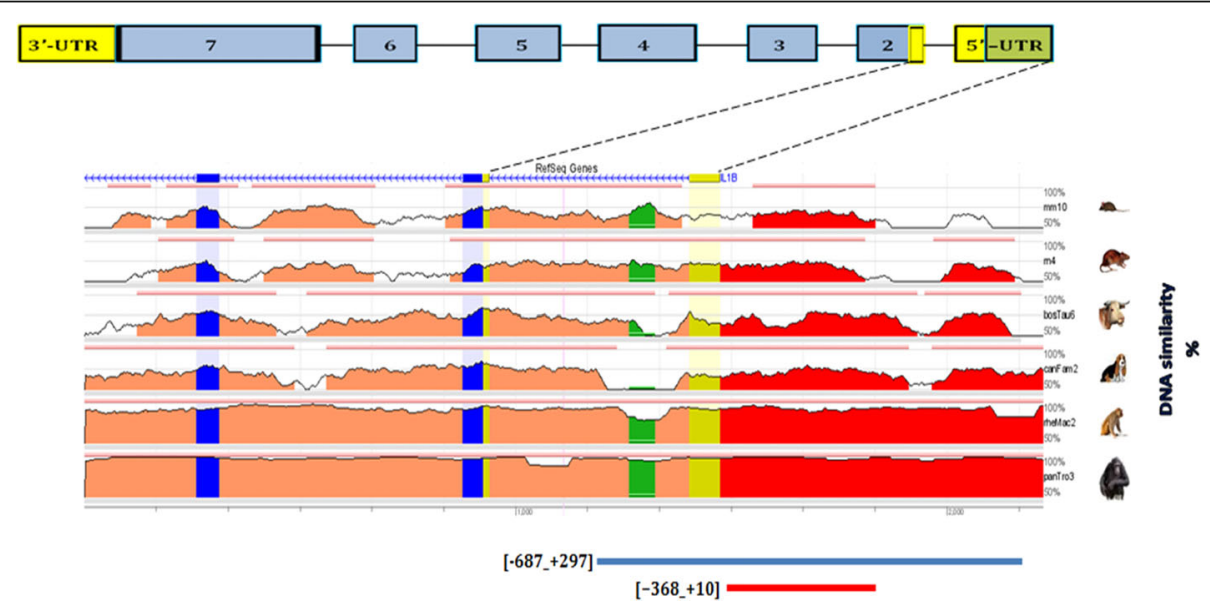

Fig. 2 Shows conservation of the IL1B 5'-upstream region compared to the human sequence in region [-687_+ 297] (hg19 chr2:113594193113,594,801). The height of the conservation plot at each position represents the number of nucleotides conserved in a window of 100 nucleotides centered on that position. The pink rectangles at the top of the plot represent the evolutionary conserved regions, which are defined as regions of 100 nucleotides with at least 70\% identity. Blue boxes represent the IL1B exons, while yellow boxes indicate the IL1B 5'-UTR. Intragenic positions are highlighted in red, or in green when corresponding to transposable elements and simple repeats. Overview from the ECR Browser [37] 
Table 3 Summary of the in silico predicted TFBSs for the $[-368++10]$ region

\begin{tabular}{|c|c|c|c|c|c|c|c|c|}
\hline \multirow{2}{*}{$\begin{array}{l}\text { Transcription } \\
\text { factor }\end{array}$} & \multicolumn{2}{|c|}{ Position $^{a}$} & \multirow[t]{2}{*}{ SNP in binding site } & \multicolumn{5}{|l|}{ Software } \\
\hline & Start & End & & AliBaba2.1 & Alggen Promo & Tfsitescan & TF-Binding & GPMine \\
\hline$\overline{G R}$ & -345 & -327 & $\begin{array}{l}\text { rs140623868 } \\
\text { NG_008851.1:g.4666 A > T }\end{array}$ & $x$ & $x$ & $x$ & $x$ & \\
\hline NF-kappaB & -297 & -288 & & $x$ & $x$ & $x$ & $x$ & \\
\hline c-Myb & -269 & -260 & rs769027934 & & $x$ & $x$ & $x$ & \\
\hline Oct-1 & -233 & -225 & & $x$ & & $x$ & $x$ & \\
\hline GATA-1 & -227 & -214 & rs749558279 & $x$ & $x$ & $x$ & $x$ & $x$ \\
\hline GR & -207 & -202 & & & $x$ & $x$ & $x$ & \\
\hline GATA-1 & -164 & -155 & $\begin{array}{l}\text { rs866837107 } \\
\text { NG_008851.1:g.4844 G > C }\end{array}$ & $x$ & $x$ & $x$ & & \\
\hline Sp1 & -149 & -132 & rs74579367 & $x$ & & $x$ & & \\
\hline AP-2 & -148 & -137 & & & & $x$ & $x$ & \\
\hline MAZ & -147 & -137 & & & $x$ & $x$ & & $x$ \\
\hline NF-Y & -126 & -114 & & & $x$ & $x$ & $x$ & \\
\hline NF-AT & -116 & -105 & & & $x$ & & & $x$ \\
\hline Spi-1/PU.1 & -115 & -97 & & $x$ & & $x$ & & \\
\hline STAT1 & -108 & -101 & & & $x$ & & $x$ & $x$ \\
\hline IRF & -106 & -99 & & & $x$ & $x$ & & \\
\hline C/EBPalpha & -94 & -83 & & & $x$ & & $x$ & $x$ \\
\hline NF-kappaB & -70 & -61 & rs4986962 & $x$ & & & $x$ & \\
\hline HSTF/HSF & -69 & -60 & & $x$ & & & $x$ & \\
\hline C/EBP & -67 & -58 & & $x$ & & & $x$ & \\
\hline Spi-1/PU.1 & -50 & -39 & & $x$ & & $x$ & & \\
\hline TBP & -31 & -25 & rs1143627 & & $x$ & & $x$ & $x$ \\
\hline$c-M y b$ & -14 & -5 & & & $x$ & & $x$ & $x$ \\
\hline NF-1 & -13 & -4 & & $x$ & $x$ & & $x$ & \\
\hline GATA-1 & -7 & 6 & rs529869449 & & $x$ & $x$ & $x$ & $x$ \\
\hline
\end{tabular}

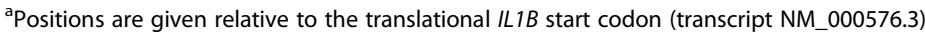

${ }^{b}$ SNPs observed in this study

the development of their own technique, and showed that although NNPP2.2 is competitive with several other freely available techniques, the technique suffers from a high level of false positives [40]. However, many studies have used this technique for promoter predictions such as [41-44]. Clearly, the result obtained by this technique or other in silico tools cannot substitute for the experimental proofs but it can provide a direction or guidance for such experiments to validate computational predictions.

Nuclease hypersensitivity and histone modifications are characteristic for cis-regulatory regions such as promoters. The ENCODE data shows these hallmarks to be present in the putative promoter region at the $+1 \mathrm{bp}$ region. The upstream region around $-124 \mathrm{bp}$ showed some of these characteristics, although to a lesser degree, while the region around $-328 \mathrm{bp}$ showed only histone marks [45-47]. Also, no CpG islands were detected in predicted promoter regions, however, most promoters with a TATA box do not have high GC content [48]. In silico comparative analysis showed the $\left[-368_{-}+10\right]$ region to be mammalian conserved, with conservation rates above $70 \%$ in chimpanzee, rhesus monkey, a domesticated dog, cow and rat. This conservation might indicate a possible regulatory role for this region (Fig. 2). But the region was not conserved in opossum, chicken, frog, zebrafish, fugu pufferfish, and spotted green pufferfish; it is possible that the regulation of IL1B in these species is controlled by a different mechanism or pathway.

Regulation of gene transcription depends on the interaction between TFs and TFBSs. Any changes in these sites may develop significant effects on the binding of TFs to regulatory sequences and then the expression products of genes $[44,49,50]$. In this study, an in silicobased prediction analysis using different algorithms indicated that the transcription factors NF, C/EBP, Spi-1/ PU.1, NF-kappaB, AP-1, TBP, IRFs and STAT, c-Myb 
a)

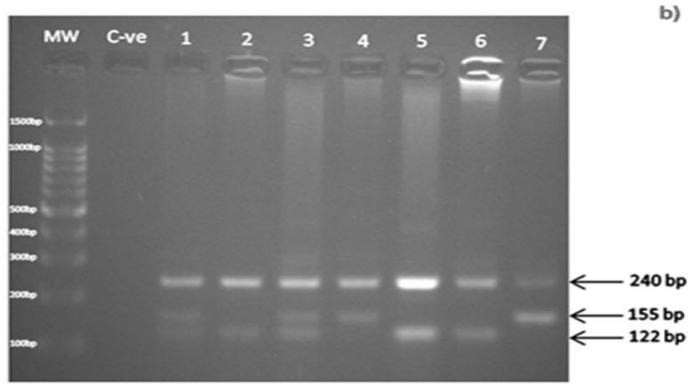

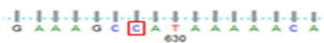

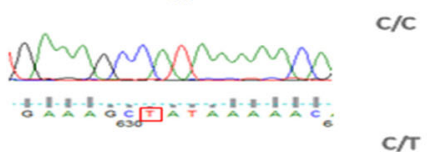

oryocxing

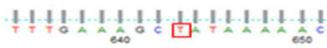

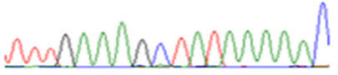

$T / T$

c)

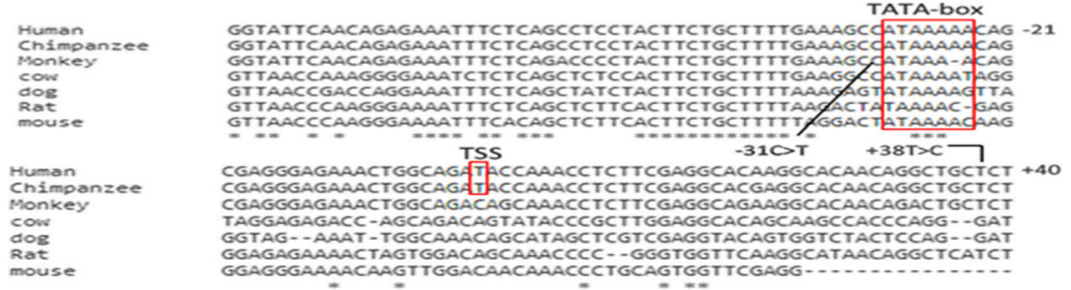

Fig. 3 a) Illustrates PCR-CTPP products analyzed on a $2 \%$ agarose gel stained with ethidium bromide. Three genotypes can be seen. 1 and 3 show $240 \mathrm{bp}, 155 \mathrm{bp}$ and $122 \mathrm{bp}$ which indicate a heterozygous genotype. 2, 5 and 6 show $240 \mathrm{bp}$ and $122 \mathrm{bp}$ which indicate a homozygous T genotype. While 4 and 7 show 240 bp and 155 bp which indicate a homozygous $C$ genotype. b) shows the sequencing result of the polymorphism by using Finch TV software. c) Illustrates the conservation of (TC; dbSNP: rs1143627) at position - 31 among different species

and GATA-1 are involved in the regulation of $I L 1 B$ gene expression and have the potential to bind in the polymorphic regions (Table 3). This indication is in agreement with the results of previous studies [26, 51, 52]. The two novel SNPs located in the in silico-predicted promoter region led to the addition or alteration of the TFBSs. As illustrated in Table 7, $-338(\mathrm{~A}>\mathrm{T})$ polymorphism resulted in the alteration of GR to PU.1 and the $-155(\mathrm{G}>\mathrm{C})$ polymorphism led to an addition of a $\mathrm{C} /$ EBPbeta. $\mathrm{T}$ allele in position -31 instead of $\mathrm{C}$ allele resulted in an addition of RSRFC4 protein. This finding is partially in agreement with experiments that assessed allele-specific oligonucleotides for -31 . The experiments reported that there were one or more TFs resulting in a fivefold increase in DNA binding on the $I L 1 B-31 \mathrm{~T}$ oligonucleotide after LPS stimulation. These TFs may be unable to interact with the C-bearing IL1B-31 allele to form the transcription initiation complex [53].

The extensively studied SNPs in relation to $H$. pylori infection $(-31$ and -511$)$ were also detected in our

a)

rs16944

$-511 T>C$

Human

Chimpanzee

Monkey

cow

$\operatorname{dog}$

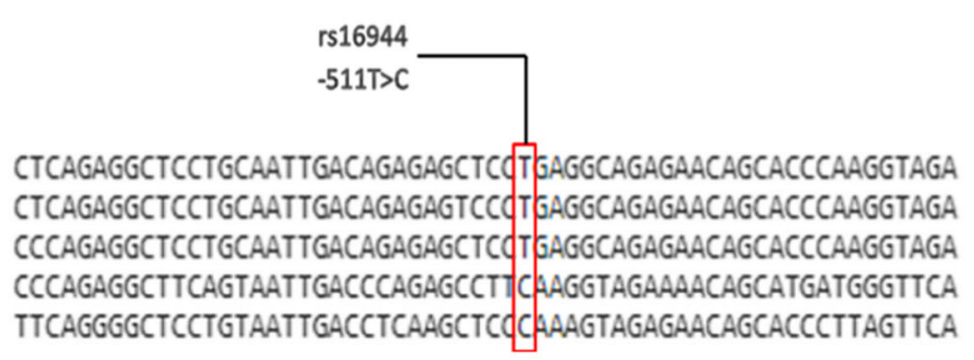

b)
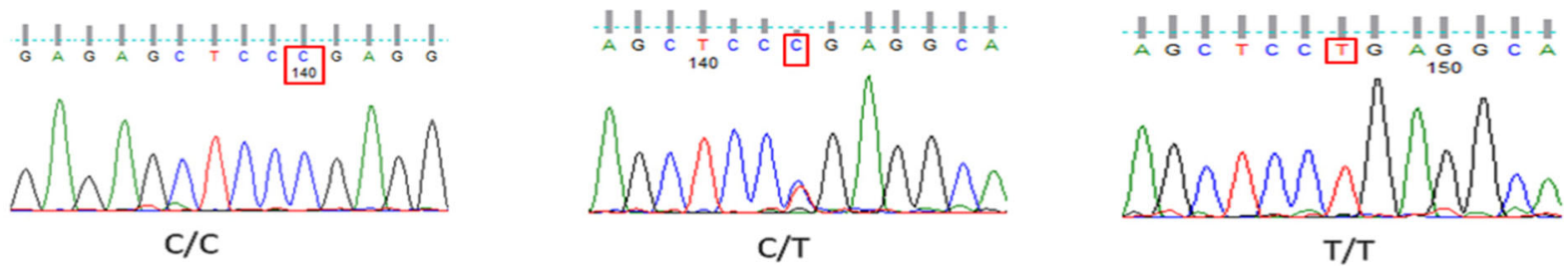

Fig. 4 a) Conservation of (CT; dbSNP: rs16944) at position - 511 among various species. b) shows the chromatogram results of the polymorphism by using Finch TV software 


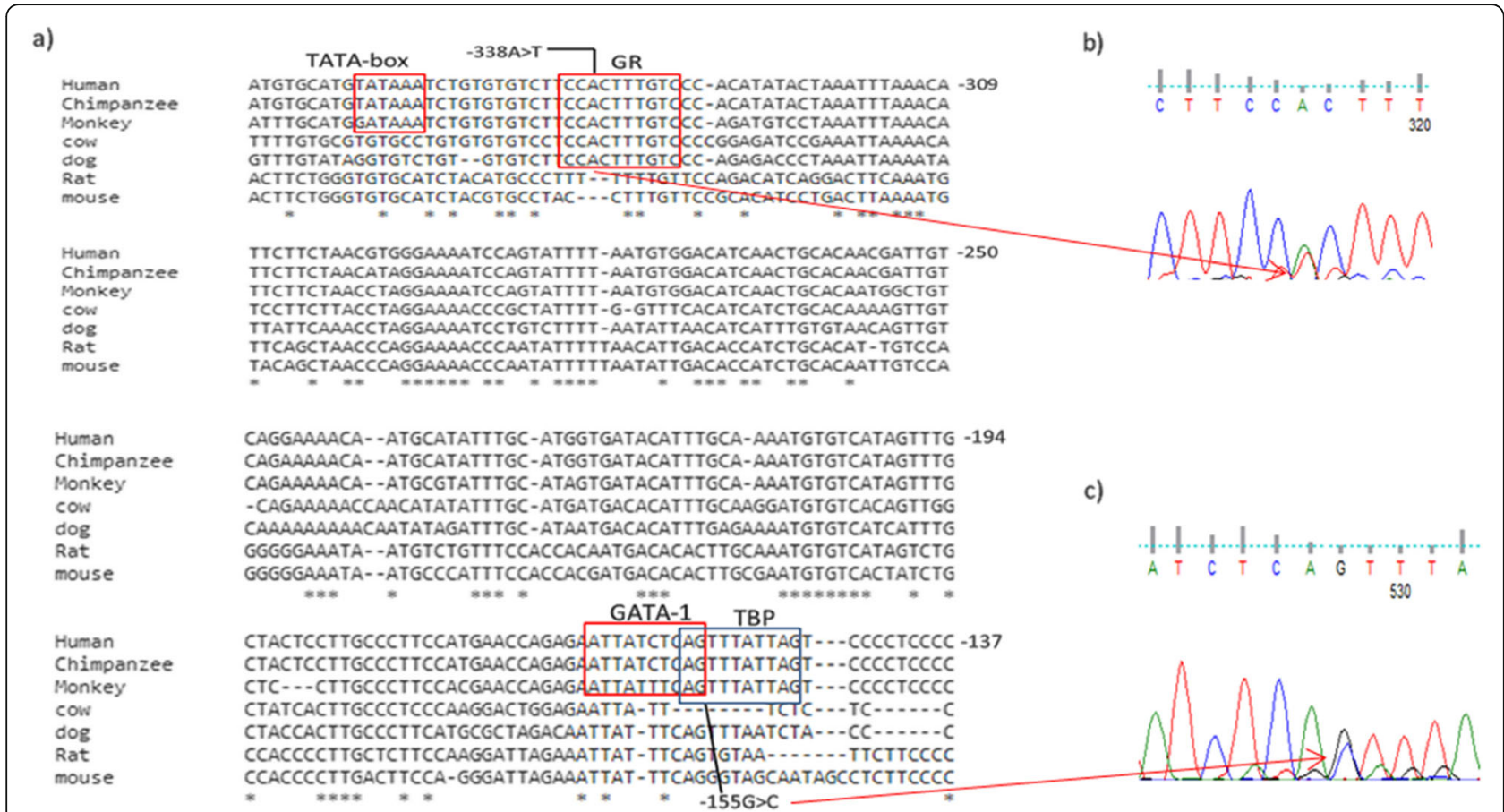

Fig. 5 a) Overview on the mammalian conservation of -338 A $>$ T and $-155 G>C$ SNPs. The nucleotides are enumerated at each line on the right side. The in silico predicted TATA- and TFBSs are marked in boxes. b) and c) Shows the chromatogram results of the polymorphisms by using Finch TV software

patients. We observed a significant association between $-31 \mathrm{~T}$ and susceptibility to $H$. pylori infection in the studied population $(\mathrm{P}=0.0363)$. This result is in concordance with a number of studies conducted in different ethnic groups that showed an association between IL1B-31 T and H. pylori infection [53-58]. Also, there are some studies that found a negative association [33, $58,59]$. This variation could be due to differences in genetic backgrounds of the studied population, the method of genotyping and sample size $[36,60]$. Interestingly, we found that the T-511C SNP was not located in the in silico-predicted promoter regions, hence it could

Table 4 Conserved TFBSs predicted by Mulan (https://mulan.dcode.org/) to be conserved (100\%) between human, chimpanzee, rhesus monkey, cow and domesticated dog at the $[-368+10]$ region. The most important transcription factor Sp1 for IL1B transcription was not included in this list

\begin{tabular}{|c|c|c|c|c|}
\hline \multirow{2}{*}{$\begin{array}{l}\text { Transcription } \\
\text { Factor }\end{array}$} & \multirow[t]{2}{*}{ Binding sequence } & \multicolumn{2}{|c|}{ Position $^{a}$} & \multirow[t]{2}{*}{ Conserved SNPs } \\
\hline & & Start & End & \\
\hline HNF4_01 & TCTTCCACTTTGTCCCACA & -344 & -326 & \multirow{4}{*}{$\begin{array}{l}\mathrm{rs} 140623868[-335] \\
-338 \mathrm{~A}>\mathrm{T}^{\mathrm{b}}\end{array}$} \\
\hline DR1_Q3 & TCCACTITGTCCC & -341 & -329 & \\
\hline PPAR_DR1_Q2 & TCCACTITGTCCC & -341 & -329 & \\
\hline NFKAPPAB65_01 & GGAAAATCCA & -295 & -286 & \\
\hline OCT1_01 & TGCATATTTGCATGGTGAT & -236 & -220 & \multirow[t]{8}{*}{ rs749558279 [-224] } \\
\hline OCT1_Q5_01 & ATATTTGCATG & -235 & -225 & \\
\hline OCT_Q6 & ATATTTGCATG & -235 & -225 & \\
\hline OCT1_B & TATTTGCATG & -234 & -225 & \\
\hline AP1_Q2_01 & CAAAATGTGTCA & -212 & -201 & \\
\hline ZTA_Q2 & TGTGTCATAGTIT & -207 & -196 & \\
\hline CEBPDELTA_Q6 & GATTGTGAAATC & -93 & -82 & \\
\hline BARBIE_01 & ACTTCTGCTITGAA & -49 & -35 & \\
\hline
\end{tabular}

${ }^{a}$ All positions are given in base pairs relative to the translational IL1B start codon (transcript NM_000576.3)

${ }^{\mathrm{b}}$ Observed in this study 
Table 5 Summary of the in silico predicted CE for the $[-368++10]$ region

\begin{tabular}{|c|c|c|c|c|c|c|c|c|c|c|}
\hline$\overline{\mathrm{CE}}$ & $\begin{array}{l}\text { MatrixName } \\
\text { for a } 1 \mathrm{st} \\
\text { element }\end{array}$ & $\mathrm{S}_{1}$ & $\begin{array}{l}\text { Distance } \\
\text { in } \\
\text { between }\end{array}$ & $\begin{array}{l}\text { MatrixName } \\
\text { for a 2nd } \\
\text { element }\end{array}$ & $S_{2}$ & Position $^{a}$ & orientation & CS & $\begin{array}{l}P \text { - } \\
\text { Value }\end{array}$ & Sequence \\
\hline CE00047 & V\$POU1F1_Q6 & 0.935 & -1 & V\$OCT1_04 & 0.949 & -239 & - & -0.004 & $\begin{array}{l}7.72 \mathrm{e}- \\
06\end{array}$ & ATGCATATTTGCATGGTGATAC \\
\hline CE00058 & $\begin{array}{l}\text { V\$NNFKB_Q6_ } \\
01\end{array}$ & 0.937 & 5 & V\$HMGIY_Q6 & 0.995 & -300 & + & -0.46 & $\begin{array}{l}1.22 e^{-} \\
05\end{array}$ & ACGTGGGAAAAT \\
\hline CE00158 & V\$OCT_C & 0.907 & 10 & V\$AP1_01 & 0.869 & -236 & - & -0.232 & $\begin{array}{l}1.88 e^{-} \\
04\end{array}$ & CATATTTGCATGGTGATACATTT \\
\hline CE00058 & $\begin{array}{l}\text { V\$NFKB_Q6_ } \\
01\end{array}$ & 0.791 & 6 & V\$HMGIY_Q6 & 0.995 & -301 & + & -0.181 & $\begin{array}{l}1.05 e^{-} \\
03\end{array}$ & AACGTGGGAAAAT \\
\hline CE00186 & V\$SETS_Q6 & 0.936 & 13 & V\$CEBPA_01 & 0.942 & -107 & - & -1.049 & $\begin{array}{l}6.55 e^{-} \\
03\end{array}$ & CTITCCTTTaactTGATTGTGAAATCA \\
\hline CE00249 & V\$IRF_Q6 & 0.924 & 5 & V\$PU1_Q6 & 0.839 & -111 & + & -0.314 & $\begin{array}{l}1.01 e^{-} \\
02\end{array}$ & TCCCCTITCCTाT \\
\hline CE00078 & V\$GR_Q6 & 0.914 & 39 & V\$CEBPB_02 & 0.799 & -377 & + & 0.049 & $\begin{array}{l}2.37 e- \\
02\end{array}$ & $\begin{array}{l}\text { GAAGAAAAGTATGTGCATGT } \\
\text { ataaatctgtgtgtcttcCACTITGTCCCACAT }\end{array}$ \\
\hline CE00186 & V\$̦ETS_Q6 & 0.896 & 20 & V\$CEBPA_01 & 0.942 & -120 & - & -0.793 & $\begin{array}{l}2.73 e^{-} \\
02\end{array}$ & $\begin{array}{l}\text { TाTCCCCC } \\
\text { TttcctttaactTGATTGTGAAATCA }\end{array}$ \\
\hline CE00135 & V\$ETS_Q6 & 0.781 & 25 & V\$MYB_Q5_01 & 0.974 & -292 & - & 0.002 & $\begin{array}{l}4.31 e^{-} \\
02\end{array}$ & $\begin{array}{l}\text { AAATCCAG } \\
\text { TattttaatgtggacatCAACTGCAC }\end{array}$ \\
\hline
\end{tabular}

CE Composite regulatory element, $S_{1,2}$ PWM scores for the first and second elements, CS Composite score ${ }^{a}$ Beginning of the element relative to TSS

not affect the expression of IL1B. While - 31 which involves a TATA-box could directly affect the induction of $I L 1 B$. These findings are in agreement with the result obtained by Al-Omer et al. that the -31 polymorphism was markedly affecting DNA-protein interactions in vitro while -511 does not alter in vitro protein secretion and its effect may be mediated by linkage disequilibrium (LD) with - 31 [53]. Also, R Kimura et al. found that the expression of the $-31 \mathrm{~T}$ allele was 2.2 times of the $-31 \mathrm{C}$ allele and this higher transcription efficiency may correspond to the fact that $\mathrm{C}-31 \mathrm{~T}$ is located in a TATA box [61]. In contrast, other observations of IL-1 $\beta$ production have

Table 6 Allele and genotype frequencies of IL $1 B-31$ polymorphism among $H$. pylori infected and uninfected subjects, and their contributions to $H$. pylori infection

\begin{tabular}{|c|c|c|c|}
\hline & $\begin{array}{l}\text { H. pylori (+ve) } \\
n=61\end{array}$ & $\begin{array}{l}\text { H. pylori (-ve) } \\
n=61\end{array}$ & OR $(95 \% \mathrm{CI})^{*}$ \\
\hline \multicolumn{4}{|c|}{ Allele frequency } \\
\hline ILIB-31-C & $77(63.11 \%)$ & $93(76.23 \%)$ & $0.5336(0.3060-0.9304)$ \\
\hline ILIB-31-T & 45 (36.89\%) & $29(23.77 \%)$ & \\
\hline P-value & 0.0363 & & \\
\hline \multicolumn{4}{|c|}{ Genotype frequency } \\
\hline $\mathrm{C} / \mathrm{C}$ & $28(45.90 \%)$ & $40(65.57 \%)$ & 1 (reference) \\
\hline $\mathrm{T} / \mathrm{C}$ & $21(34.41 \%)$ & $13(21.31 \%)$ & $0.4333(0.1864-1.008)$ \\
\hline$T / T$ & $12(19.67 \%)$ & $8(13.12 \%)$ & $0.4667(0.1688-1.290)$ \\
\hline $\mathrm{T} / \mathrm{C}+\mathrm{T} / \mathrm{T}$ & $33(54.1 \%)$ & $21(34.43 \%)$ & $0.4455(0.2147-0.9243)$ \\
\hline P-value & 0.0445 & & \\
\hline
\end{tabular}

"OR, odds ratio; $95 \% \mathrm{Cl}, 95 \%$ confidence interval suggested that there was no significant association between the known allelisms in the $I L-1 B$ gene and IL- $1 \beta$ induction in vitro and that the $-31 \mathrm{C}$ was the higher expressing allele in vivo [61-63]. However, the production of IL1 $\beta$ is affected by several factors besides gene polymorphisms such as epigenetic conditions and other genetic backgrounds. To exclude the influence of trans-acting factors which are able to confound the effects of the polymorphisms, the allele-specific transcript quantification coupled with haplotype analysis [61, 64] is recommended to identify the cis-acting effect of $\mathrm{T}-511 \mathrm{C}$ polymorphism

Table 7 Variations in transcription factors before and after nucleotide changes $(-338,-155$ and -31$)$ in the IL1B gene by using AliBaba2.1 software

\begin{tabular}{lllll}
\hline SNP Site & Base Group & TF & TFBSs Sequence & TF Position \\
\hline-338 & A & GCR1 & CTTCCACTT & $-343_{-}-334$ \\
& & GR & CACTTTGTCC & $-339_{-}-330$ \\
& T & PU.1 & CTTCCTCTT & $-343_{-}-334$ \\
& & GCR1 & & \\
-155 & G & Zen-1 & ATTATCTCAG & $-164_{-}-155$ \\
& & GATA-1 & TTATCTCAG & $-163_{-}-154$ \\
& C & C/EBPbeta & ATTATCTCAC & $-164_{-}-155$ \\
& & Zen-1 & & \\
& & GATA-1 & TTATCTCACT & $-163 \ldots-154$ \\
-31 & $C$ & - & - & - \\
& $T$ & RSRFC4 & GCTATAAAAA & $-33 \_-24$ \\
\hline
\end{tabular}


and our novel detected polymorphisms (- 338 and - 155) on the $I L 1 B$ transcription and susceptibility to multifactorial diseases including $H$. pylori infection.

However, recognition of regulatory motifs by computer algorithms is fundamental for understanding gene expression patterns, as well as, cell specificity and development [49]. Identifying SNPs that might be a genetic modifiers in $I L 1 B$ gene may be valuable in preventive, diagnostic, and therapeutic strategies against the incidence and progression of $H$. pylori infection. This study revealed three nucleotide variations in the IL1B 5'-region which possibly lead to modification of transcriptional regulation in $\mathrm{H}$. pylori infection, however, this conclusion requires further in vitro and in vivo validation in subsequent studies.

\section{Conclusions}

In H. pylori-infected patients, three detected SNPs located in the $I L 1 B$ promoter were predicted to alter CEs and TFBSs, which might affect the gene expression. This computational analysis provide insight for further experimental in vitro and in vivo studies of the regulation of $I L 1 B$ expression and its relationship to $H$. pylori infection. However, recognition of regulatory motifs by computer algorithms is fundamental for understanding gene expression patterns.

\section{Methods}

\section{Study methodology}

In this study, genomic DNA Sanger sequencing was used to detect SNPs in the region [-687_+ 297] of IL1B in 14
H. pylori-infected patients. Then, computational analyses of the $I L-1 B$ promoter region [-687_+ 297] were applied in two steps: 1) in silico prediction of the promoter region and 2) in silico analysis of the predicted promoter region $\left[-368_{-}+10\right]$. Furthermore, genotyping of $I L 1 B-31$ $\mathrm{C}>\mathrm{T}$ polymorphism was performed using PCR-CTPP in 122 participants to study its association with the susceptibility to $H$. pylori infection in the Sudanese population. The methodology followed in this study is described in Fig. 6.

\section{Study setting and study population}

This study was carried out at public and private hospitals in Khartoum state. The hospitals included Ibin Sina specialized hospital, Soba teaching hospital, Modern Medical Centre and Al Faisal Specialized Hospital. Sample size was calculated using Epi Info software version 7 $[65,66]$. The matched case-control formula was selected assuming 95\% confidence level, $80 \%$ power of study, 1 ratio of control to case, $15 \%$ of controls exposed, 3.36 odds ratio and $37.2 \%$ of cases exposed. Based on the sample size calculation, a total of 122 individuals were recruited for this study.

The 122 participants had been referred for endoscopy. Out of that, 15 had gastric cancer, 27 had peptic ulceration, 61 had gastroduodenal inflammation, 10 had esophageal diseases, while nine showed normal upper gastroduodenoscopic features. The diagnosis of gastroduodenal diseases had been made by an experienced gastroenterologist during the upper gastrointestinal (GI)

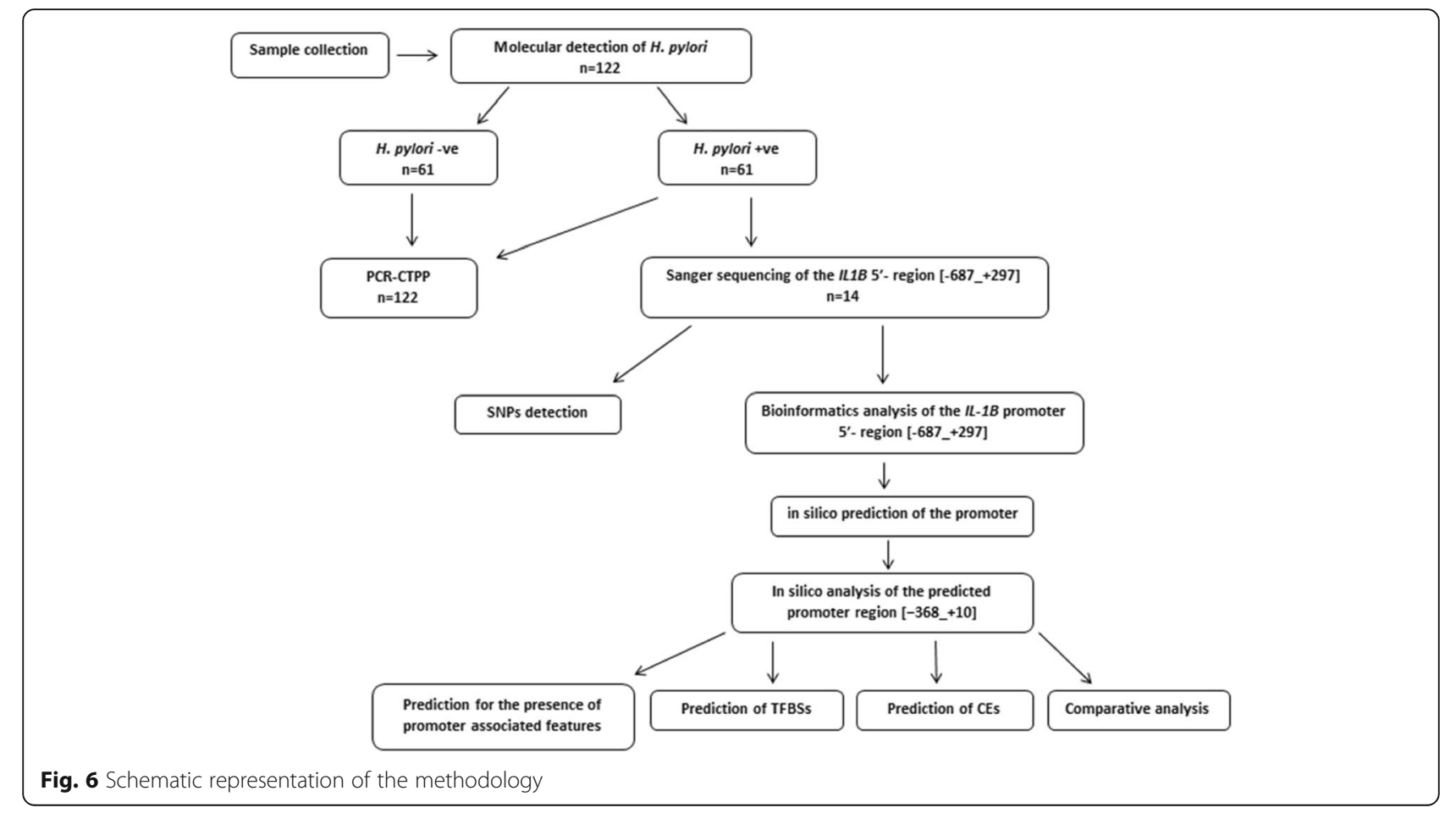


endoscopy procedure. While gastric cancer was diagnosed based on histology. Participants' demographic and clinical data were obtained by a structured questionnaire, personal interviews, and a review of case records. The selection criteria included the Sudanese population from both sexes, no antibiotic or non-steroidal antiinflammatory drugs (NSAIDs) uses. All the participants were informed with the objectives and purposes of the study and the written informed consents were taken. The demographic characteristics of participants is presented in Table 8.

\section{DNA extraction}

Gastric biopsies were collected in $400 \mu$ phosphate buffer saline (PBS). For histological examination, the biopsies were transported in formalin. DNA extraction was carried out by using innuPREP DNA Mini Kit (analytikjena AG, Germany) according to the protocol given by the manufacturer, as previously described in [67].

\section{PCR amplification of specific $16 \mathrm{~S}$ rRNA of $H$. pylori}

The specific $16 S$ rRNA gene of $H$. pylori was amplified by using the following primers (primers: F: $5^{\prime}$-GCGCAA TCAGCGTCAGGTAATG-3') (R:5'-GCTAAGAGAG CAGCCTATGTCC-3') [68]. The PCR condition was previously described [69].

\section{PCR amplification and sequencing of the IL1B promoter region}

The $I L-1 B-511$ and -31 , promoter polymorphisms, were amplified using the following primers: F:5' - CATCCA 'TGAGATTGGCTAG-3' and R:5' - AGCACCTAGT TGTAAGGAAG-3' [70]. The cycling conditions were an initial denaturation at $94^{\circ} \mathrm{C}$ for $5 \mathrm{~min}$, followed by 35 cycles of $94^{\circ} \mathrm{C}$ for $1 \mathrm{~min}, 60^{\circ} \mathrm{C}$ for $1 \mathrm{~min}$ and $72^{\circ} \mathrm{C}$ for 1 min, with a final extension at $72{ }^{\circ} \mathrm{C}$ for $7 \mathrm{~min}$. The amplified PCR product is $800 \mathrm{bp}$ and was located between $687 \mathrm{bp}$ upstream and +297 bp downstream of the $I L-1 B$ gene.

Out of 14 PCR products of $H$. pylori-infected subjects, which have the clearest bands, were sent for DNA purification and Sanger dideoxy sequencing. Both DNA strands were sequenced commercially by Macrogen Inc., Korea.

\section{Sequence analysis and SNPs detection}

The sequencing results, two chromatograms for each patient (forward and reverse), were visualized, checked for quality, and analyzed using the Finch TV program version 1.4.0 [71]. The nucleotide Basic Local Alignment Search Tool (BLASTn; https://blast.ncbi.nlm.nih.gov/) was used to assess nucleotide sequence similarities [72].

To determine the SNPs in the $I L-1 B$ promoter region, multiple sequence alignment (MSA) for tested sequences with a reference sequence (NG_008851) were performed by using BioEdit software [73].

\section{Bioinformatics analysis of the $I L-1 B$ promoter region in $H$. pylori-infected subjects \\ In silico prediction of the promoter}

The crucial element for initiating and regulating messenger RNA transcription is the promoter sequence which is generally located in the $5^{\prime}$ upstream region of a structural gene [44]. Promoters have complex and specific architecture, and contain multiple TFs involved in specific regulation of transcription [74]. Different features of a promoter region may have different power for promoter identification [49], therefore, we applied a variety of programs for prediction of promoter regions in order to obtain accurate results for subsequent experimental proof. These programs include: (1) Promoter 2.0 Prediction Server (http://www.cbs.dtu.dk/) which takes advantage of a combination of elements similar to neural networks and genetic algorithms to recognize a set of discrete sub-patterns with variable separation as one pattern: a promoter [75]; (2) Neural Network Promoter Prediction (NNPP2.2) (http://www.fruitfly.org/) which applying multiple hidden layers and time-delay neural networks (TDNNs) for promoter annotation [76]; (3) TSSW (http://softberry.com/) that uses functional motifs from the Wingender et al. database [77] and linear discriminant function combining characteristics describing function motifs and oligonucleotide composition of these sites [78]; (4) TSSG program (http://softberry.com/

Table 8 Demographic characteristic of participants

\begin{tabular}{|c|c|c|c|c|}
\hline Variables & $\begin{array}{l}\text { Total } \\
n=122\end{array}$ & $\begin{array}{l}\text { H. pylori (+ve) } \\
\mathrm{n}=61\end{array}$ & $\begin{array}{l}\text { H. pylori (-ve) } \\
n=61\end{array}$ & P-value \\
\hline Age years \pm Std. Deviation (range) & $44.37 \pm 17.48(15-89)$ & $44.00 \pm 16.99(15-85)$ & $44.74 \pm 18.10(17-89)$ & 0.9184 \\
\hline \multicolumn{5}{|l|}{ Gender } \\
\hline Male & $72(59.02 \%)$ & $36(50 \%)$ & $36(50 \%)$ & \multirow[t]{2}{*}{1.0000} \\
\hline Female & $50(40.98 \%)$ & $25(50 \%)$ & $25(50 \%)$ & \\
\hline \multicolumn{5}{|l|}{ Residence } \\
\hline Urban & $54(44.26 \%)$ & $24(44.44 \%)$ & $30(55.56 \%)$ & \multirow[t]{2}{*}{0.3622} \\
\hline Rural & $68(55.74 \%)$ & $37(54.41 \%)$ & $31(45.59 \%)$ & \\
\hline
\end{tabular}


) program that uses the same approach of TSSW but the TFD database of functional motifs [79]; (5) Fprom program (http://softberry.com/) which is TSSG variant with different learning set of promoter sequences [49].

\section{In silico analysis of the predicted promoter region}

\section{Assessment for the presence of promoter associated} features In silico predicted promoter region was additionally assessed for the presence of promoter associated features, including promoter-associated histone marks, broad chromatin state segmentation, transcription factor ChIP-seq, and DNase I hypersensitivity clusters, using the ENCODE data (https://epd.epfl.ch/cgibin/get_doc?db=hgEpdNew\&format=genome\&entry=IL1 B_1) [45-47].

Prediction of CpG Islands A CpG island is often regarded as a marker for the initiation of gene expression. It is a segment of DNA with high GC and CpG dinucleotide contents which is located in the $5^{\prime}$ UTR (untranslated regions) of genes. In this study, MethPrimer $[44,80]$ and $\mathrm{GpC}$ finder software (http://www. softberry.com/berry.phtml?topic $=$ cpgfinder\&group $=$ programs\&subgroup=promoter) were employed to predict $\mathrm{CpG}$ islands in the promoter. CpG finder is intended to search for $\mathrm{CpG}$ islands in sequences, while MethPrimer is developed to design PCR primers for methylation mapping and primers are picked around the predicted $\mathrm{CpG}$ islands. CpG islands are predicted by using a simple sliding window algorithm to examine the GC content and the ratio observed/expected (Obs/Exp) across the sequence. The search parameter values for the software were CpG island length $>200 \mathrm{bp}, \mathrm{CG} \%>$ $50 \%$, and $\mathrm{Obs} / \operatorname{Exp}>0.6$.

Prediction of transcription factor binding sites (TFBSs) One of the important steps in the chain of promoter analytical events is the prediction of the potentially functional TFBSs. Protein binding sites in a promoter represent the most important elements and the corresponding proteins are called transcription factors (TFs). In this step, the promoter region was analyzed for possible TFBSs using five prediction software. (1) Alggen Promo (http://alggen.lsi.upc.es/cgi-bin/ promo_v3/) in which positional weight matrices (PWM) are constructed from known binding sites extracted from TRANSFAC [38] and used for the identification of potential binding sites in sequences [81, 82]. (2) Ali$\mathrm{BaBa} 2$ (http://www.gene-regulation.com/) which works based on the assumption that each binding site has an unknown context that determines its sequence and this leads to a construct of specific matrices for each sequence we are analyzing. And to do so a context-specific process starting at a dataset of known binding sites and ending with the identification of a potential new binding site [83]. (3) Gene Promoter Miner (GPMiner) (http:// GPMiner.mbc.nctu.edu.tw/) which is an integrated system that identifies promoter regions, regulatory elements and DNA stability by incorporating the support vector machine (SVM) with nucleotide composition features, over-represented hexamer nucleotides, and DNA stability. For predicting TFBSs, MATCH tool [84] was utilized to scan TFBSs in an input sequence using the TF binding profiles from TRANSFAC public release version 7.0 [85] and JASPAR [86, 87]. (4) TF-Bind (http://tfbind.hgc. $\mathrm{jp} /$ ) which uses positional weight matrices (PWMs) and Bucher's calculating method [88] to calculate the matching score between an input sequence and a set of known TF binding sites. To estimate TF binding sites, a robust cut-off value determining algorithm was proposed using the background rate estimated on non-promoters sequences [89]. (5) Tfsitescan (http://www.ifti.org) which is an object-oriented transcription factors database (ooTFD)-retrieval tool that is used for transcription factors sites analyses. It constructs an image-map in association with sequence analysis results which is linked to individual sites entries [90].

Prediction of composite regulatory elements (CEs) $\mathrm{CE}$ is the minimal functional unit, which can provide combinatorial transcriptional regulation of gene expression. Structurally, a CE consists of two closely located DNA binding sites (BSs) for distinct transcription factors. But its regulatory function is qualitatively different from regulation effects of either individual DNA binding sites. In this study, we identified the composite regulatory elements in our region by using MatrixCatch algorithm (http://gnaweb.helmholtz-hzi.de/cgi-bin/MCatch/ MatrixCatch.pl). The basic idea of MatrixCatch is to recruit data collected for respective binding sites separately from each other in order to complement the lack of knowledge on sequence variation of each DNA BS in CEs, and such information is compiled in position weight matrices (PWMs). The CE model consists of two PWMs, as well as their minimal scores, relative orientation and distance. Moreover, MatrixCatch is supplied with a library of 265 matrix models used for recognition which represents the widest scope of known CEs available to date [91].

Comparative analysis Promoter region was analyzed for possible conservation using the ECR Browser (http:// ecrbrowser.dcode.org) [37], NCBI BLASTn (http://blast. ncbi.nlm.nih.gov/Blast.cgi) and ClustalW (https://www. genome.jp/tools-bin/clustalw). Conservation was assessed in 11 species: chimpanzee (Pan troglodytes), rhesus monkey (Macacamulatta), mouse (Mus musculus), rat 
(Rattusnorvegicus), dog (Canisfamiliaris), cow (Bostaurus), opossum (Monodelphisdomestica), chicken (Gallus gallus), frog (Xenopuslaevis), zebrafish (Danio rerio), fugu pufferfish (Takifugurubripes), and spotted green pufferfish (Tetraodon nigrovoridis).

Also, conservation of SNPs was evaluated and the possible conservation of TFBSs at these SNP locations was screened with Multiple-sequence local alignment and visualization (Mulan) search engine (https://mulan. dcode.org/) [92].

\section{Detection of the IL-1B-31 C/T polymorphism using PCR with confronting two-pair primer (PCR-CTPP)}

For detection of the $I L-1 B-31$ polymorphism, PCR-CTPP was applied. The primers for the $\mathrm{C}$ allele were (F:5'ACT TCT GCT TTT GAA GGC C-3') and (R:5'-TAG CAC CTA GTT GTA AGG A-3'); and those for the T allele were (F:5' -AGA AGC TTC CAC CAA TAC T-3') and (R:5'-CTC CCT CGC TGT TTT TAT A-3') [93]. One $\mu \mathrm{l}$ of extracted DNA was used in a $25 \mu \mathrm{l}$ reaction mixture with a prepared Maxime PCR PreMix Kit (iTaq) (iNtRON BIOTECHNOLOGY, Seongnam, Korea), $23 \mu \mathrm{l}$ of de-ionized sterile water, $0.25 \mu \mathrm{l}$ of each primer. PCR conditions were as follow: $5 \mathrm{~min}$ of initial denaturation at $94{ }^{\circ} \mathrm{C}$, followed by 25 cycles of 1 min at $94{ }^{\circ} \mathrm{C}, 1$ min at $54^{\circ} \mathrm{C}$, and $1 \mathrm{~min}$ at $72^{\circ} \mathrm{C}$, and a $5 \mathrm{~min}$ final incubation at $72{ }^{\circ} \mathrm{C}$. The PCR products were visualized by electrophoresis on a $2 \%$ agarose gel stained with ethidium bromide. Genotyping was performed as follows; 240, 155 bp for CC genotype, 240, 155, 122 bp for CT genotype, and 240, $122 \mathrm{bp}$ for TT genotype [93].

\section{Statistical analysis}

Deviations from Hardy-Weinberg equilibrium in control were examined by $\chi^{2}$ test. According to prevalence of $H$. pylori infection, differences in distribution by age were assessed by Mann-Whitney test, while differences in distribution by categorical variables were examined by $\chi^{2}$ test or Fisher's test. Odds ratios (ORs) were calculated and reported within the $95 \%$ confidence intervals (CIs). $P<0.05$ was considered to be statistically significant. The statistical analyses were performed using the GraphPad Prism 5.

\section{Supplementary Information}

The online version contains supplementary material available at https://doi. org/10.1186/s12866-020-02072-3.

Additional file 1. The structured questionnaire.

Additional file 2. Original, full-length gel and blot images.

\section{Abbreviations}

165 rRNA: 16 Svedberg ribosomal RNA; AP-1: Activator protein 1; BDGP: Berkeley Drosophila Genome Project; BLASTn: The nucleotide Basic Local Alignment Search Tool; bosTau3: Bos Taurus (cow) full genome as provided by UCSC (Jan 2008); bp: base pair; C/ EBPß: CCAAT-enhancer binding protein beta; C/EBPa: CCAAT-enhancer binding protein alpha; canFam2: Canis lupus familiaris (domesticated dog) full genome as provided by UCSC (Jan 2008); CE: Composite regulatory element; ChIP-seq: Chromatin Immunoprecipitation Sequencing; Cl: Confidence interval; CS: Composite score; CTPP: Confronting two-pair primer; DR1: Down-regulator of transcription 1; ECR: Evolutionary conserved region; ENCODE: Encyclopedia of DNA elements; FPROM: Human promoter prediction; GATA-1: Globin transcription factor 1; GR: Glucocorticoid receptor; H. pylori: Helicobacter pylori; hg19: Homo sapiens (Human) full genome as provided by UCSC (Feb 2009); HNF4: Hepatocyte nuclear factor 4; HSF: Heat-shock factor; HSTF: Heat shock transcription factor; HWE: Hardy-Weinberg equilibrium; IL-1: interleukin 1; IL 1A: interleukin 1-alpha; IL1B: interleukin 1-beta; IL-1RN: interleukin 1 receptor antagonist; IRF: Interferon-regulatory factor; LD: Linkage disequilibrium; LDF: Linear discriminant factor; LPS: Lipopolysaccharide; MALT: Mucosaassociated lymphoid tissue lymphoma; MAZ: Myc-associated zinc finger protein; mm9: Mus musculus (mouse) full genome as provided by UCSC (Jan 2008); MSA: Multiple sequence alignment; Mulan: Multiple-sequence local alignment and visualization; NCBI: National Center for Biotechnology Information; NF-AT: Nuclear factor of activated T cells; NF-Y: Nuclear transcription factor Y; NF-kB: Nuclear factor Kappa $\beta$; NK: Natural killer cell; NNPP: Neural Network Promoter Prediction; NSAIDS: Non-steroidal antiinflammatory drugs; Oct-1: Octamer transcription factor; OR: Odds ratio; panTro2: Pan troglodytes (chimpanzee) full genome as provided by UCSC (Jan 2008); PBS: Phosphate buffer saline; PCR: Polymerase chain reaction; PPAR: Peroxisome proliferator-activated receptor; PWM: Position weight matrices; rheMac2: Macaca mulatta (rhesus monkey) full genome as provided by UCSC (Jan 2008); rn4: Rattus norvegicus (rat) full genome as provided by UCSC (Jan 2008); SNP: Single nucleotide polymorphism; Spi1: SV40 promoter-1; SRF: Serum response factor; SSRP: Structure specific recognition protein 1; STAT1: Signal transducer and activator of transcription 1; Std: Standard; T cell: T lymphocyte cell; T: Thymidine; TBP: TATA- binding protein; TF: Transcription factor; TFBS: Transcription factor binding site; TSS: Transcription start site; TSSG: Recognition of human Polll promoter region and start of transcription; TSSW: Recognition of human Polll promoter region and start of transcription; UTR: Unstranslated region; ZTA: The EpsteinBarr virus bZIP transcription factor

\section{Acknowledgements}

We gratefully acknowledge the participants and the staff of the gastroscopic unit in Ibin Sina specialized hospital, Soba teaching hospital, Modern Medical Centre, Al-Shorta hospital, and Al Faisal Specialized Hospital. We would also like to show our gratitude to the Department of Medical Microbiology, Faculty of Medical Laboratory Sciences, University of Khartoum for their cooperation.

\section{Authors' contributions}

$M A H$ and EMI supervised the methodology. ABI, AEA, AEAM and BMOA collected the samples. $A B I, E B I$ and $A E A$ extracted the DNA. ABI amplified the 165 rRNA and $I L 1 B$ genes. $A B I$ and $E B I$ analyzed the data. $A B I$ performed the bioinformatics and statistical analysis for the data. $A B I$ wrote the manuscript. AEAM and MAH edited and revised the manuscript. All authors have read and approved the manuscript.

\section{Funding}

The authors received no specific funding for this work.

\section{Availability of data and materials}

The data regarding $I L 1 B-31 C>T$ genotypes and alleles distributions among participants and the in silico results of software used to support the findings of this study are available from the corresponding author on easonable request.

\section{Ethics approval and consent to participate}

The study was approved by the Khartoum Ministry of Health research department, University of Khartoum, Faculty of Medical Laboratory Sciences review board, and Research Ethics Committees of hospitals. Written informed consent was taken from participants before they enrolled.

Consent for publication

Not applicable. 


\section{Competing interests}

The authors declare that there are no conflicts of interest.

\section{Author details}

'Department of Medical Microbiology, Faculty of Medical Laboratory Sciences, University of Khartoum, Khartoum, Sudan. ${ }^{2}$ Medical Laboratory Specialist, Department of Medical Microbiology, Rashid Medical Complex, Riyadh, Saudi Arabia. ${ }^{3}$ Department of Medical Microbiology, Faculty of Medical Laboratory Sciences, University of Al-Gazirah, Wad Madani, Sudan. ${ }^{4}$ Faculty of Medicine, University of Khartoum, Khartoum, Sudan. ${ }^{5}$ Department of Internal Medicine, Modern Medical Centre, Khartoum, Sudan. ${ }^{6}$ Department of Bioinformatics, Africa city of technology, Khartoum, Sudan. ${ }^{7}$ Department of Bioinformatics, DETAGEN Genetic Diagnostics Center, Kayseri, Turkey.

${ }^{8}$ Department of Translation Bioinformatics, Detavax Biotech, Kayseri, Turkey.

Received: 19 August 2020 Accepted: 15 December 2020

Published online: 07 January 2021

\section{References}

1. Moodley Y, Linz B, Bond RP, Nieuwoudt M, Soodyall H, Schlebusch CM, et al. Age of the association between Helicobacter pylori and man. PLoS Pathog. 2012;8(5):e1002693.

2. Suerbaum S, Michetti P. Helicobacter pylori infection. New England J Med. 2002;347:1175-86

3. Sjomina O, Pavlova J, Niv Y, Leja M. Epidemiology of helicobacter pylori infection. Helicobacter. 2018;23(S1):e12514.

4. Zamani M, Ebrahimtabar F, Zamani V, Miller WH, Alizadeh-Navaei R, ShokriShirvani J, et al. Systematic review with meta-analysis: the worldwide prevalence of helicobacter pylori infection. Aliment Pharmacol Ther. 2018; 47(7):868-76.

5. Goh K-L, Chan W-K, Shiota S, Yamaoka Y. Epidemiology of Helicobacter pylori infection and public health implications. Helicobacter. 2011;16 Suppl 1(1):1-9.

6. Fock KM, Ang TL. Epidemiology of helicobacter pylori infection and gastric cancer in Asia. J Gastroenterol Hepatol. 2010;25(3):479-86.

7. Chmiela M, Karwowska Z, Gonciarz W, Allushi B, Staczek P. Host pathogen interactions in helicobacter pylori related gastric cancer. World J Gastroenterol. 2017;23(9):1521-40.

8. Kodaman N, Pazos A, Schneider BG, Piazuelo MB, Mera R, Sobota RS, et al. Human and helicobacter pylori coevolution shapes the risk of gastric disease. Proc Natl Acad Sci U S A. 2014;111(4):1455-60.

9. Testerman TL, Morris J. Beyond the stomach: An updated view of helicobacter pylori pathogenesis, diagnosis, and treatment. World J Gastroenterol. 2014;20(36):12781-808

10. Cadamuro ACT, Rossi AFT, Maniezzo NM, Silva AE. Helicobacter pylori infection: host immune response, implications on gene expression and microRNAs. World J Gastroenterol. 2014;20(6):1424-37.

11. Forman D, Burley VJ. Gastric cancer: global pattern of the disease and an overview of environmental risk factors. Best Pract Res Clin Gastroenterol. 2006;20(4):633-49.

12. de Sablet T, Piazuelo MB, Shaffer CL, Schneider BG, Asim M, Chaturvedi R, et al. Phylogeographic origin of helicobacter pylori is a determinant of gastric cancer risk. Gut. 2011;60(9):1189-95.

13. Chang $\mathrm{W}-\mathrm{L}$, Yeh $\mathrm{Y}-\mathrm{C}$, Sheu B-S. The impacts of $\mathrm{H}$. pylori virulence factors on the development of gastroduodenal diseases. J Biomed Sci. 2018;25(1):68.

14. Nicklin MJH, Weith A, Duff GW. A physical map of the region encompassing the human interleukin-1a, interleukin-1 $\beta$, and Interleukin-1 receptor antagonist genes. Genomics. 1994;19(2):382-4.

15. El-Omar EM. The importance of interleukin 1beta in helicobacter pylori associated disease. Gut. 2001;48(6):743-7.

16. Dinarello CA. Interleukin-1 and interleukin-1 antagonism. Blood. 1991;77(8): 1627-52.

17. Ren K, Torres R. Role of interleukin-1beta during pain and inflammation Brain Res Rev. 2009;60(1):57-64

18. Rad R, Dossumbekova A, Neu B, Lang R, Bauer S, Saur D, et al. Cytokine gene polymorphisms influence mucosal cytokine expression, gastric inflammation, and host specific colonisation during helicobacter pylori infection. Gut. 2004;53(8):1082-9.

19. Sun X, Cai H, Li Z, Li S, Yin W, Dong G, et al. Association between IL-1b polymorphisms and gastritis risk. Medicines. 2017;96:5.
20. Motamedi Rad N, Rezaeishahmirzadi M, Shakeri S, Abbaszadegan MR, Shekari M. Association of IL-1B+3954 and IL-1RN polymorphisms in chronic gastritis and peptic ulcer. Iran J Public Health. 2018;47(9):1364-70.

21. Robert A, Olafsson AS, Lancaster C, Zhang WR. Interleukin-1 is cytoprotective, antisecretory, stimulates PGE2 synthesis by the stomach, and retards gastric emptying. Life Sci. 1991;48(2):123-34.

22. Pulugulla SH, Packard TA, Galloway NLK, Grimmett ZW, Doitsh G, Adamik J, et al. Distinct mechanisms regulate IL1B gene transcription in lymphoid CD4 T cells and monocytes. Cytokine. 2018;111:373-81.

23. Adamik J, Wang KZQ, Unlu S, Su A-JA, Tannahill GM, Galson DL, et al. Distinct mechanisms for induction and tolerance regulate the immediate early genes encoding interleukin $1 \beta$ and tumor necrosis factor a. Plos One. 2013:8(8):e70622

24. Marecki S, Riendeau CJ, Liang MD, Fenton MJ. PU.1 and multiple IFN regulatory factor proteins synergize to mediate transcriptional activation of the human IL-1 $\beta$ gene. J Immunol. 2001;166(11):6829-38.

25. Dinarello C. Biologic basis for interleukin-1 in disease. Blood. 1996;87(6): 2095-147.

26. Kominato Y, Galson D, Waterman WR, Webb AC, Auron PE. Monocyte expression of the human prointerleukin 1 beta gene (IL1B) is dependent on promoter sequences which bind the hematopoietic transcription factor Spi1/PU.1. Mol Cell Biol. 1995;15(1):59-68.

27. Auron PE, Webb AC. Interleukin-1: a gene expression system regulated at multiple levels. Eur Cytokine Netw. 1994;5(6):573-92.

28. Listman JA, Race JE, Walker-Kopp N, Unlu S, Auron PE. Inhibition of IL-1beta transcription by peptides derived from the hCMV IE2 transactivator. Mol Immunol. 2008;45(9):2667-77.

29. Zhang Y, Saccani S, Shin H, Nikolajczyk BS. Dynamic protein associations define two phases of IL-1beta transcriptional activation. J Immunol. 2008; 181(1):503-12.

30. Shirakawa F, Saito K, Bonagura CA, Galson DL, Fenton MJ, Webb AC, et al. The human prointerleukin 1 beta gene requires DNA sequences both proximal and distal to the transcription start site for tissue-specific induction. Mol Cell Biol. 1993;13(3):1332-44.

31. Ahmed AB, Zidi S, Sghaier I, Ghazouani E, Mezlini A, Almawi W, et al. Common variants in IL-1RN, IL-1beta and TNF-alpha and the risk of ovarian cancer: a case control study. Cent Eur J Immunol. 2017;42(2):150-5.

32. Figueiredo CA, Marques CR, Costa Rdos S, da Silva HB, Alcantara-Neves NM. Cytokines, cytokine gene polymorphisms and helicobacter pylori infection: friend or foe? World J Gastroenterol. 2014;20(18):5235-43.

33. Lu W, Pan K, Zhang L, Lin D, Miao X, You W. Genetic polymorphisms of interleukin (IL)-1B, IL-1RN, IL-8, IL-10 and tumor necrosis factor \{alpha\} and risk of gastric cancer in a Chinese population. Carcinogenesis. 2005;26(3):631-6.

34. Singh H, Samani D, Nema V, Ghate MV, Gangakhedkar RR. IL-1RN and IL1 beta polymorphism and ARV-associated hepatotoxicity. Mediat Inflamm. 2018;2018:4398150.

35. Shehjar F, Afroze D, Misgar RA, Malik SA, Laway BA. Association of polymorphic variants of IL-1 beta and IL-1RN genes in the development of Graves' disease in Kashmiri population (North India). Hum Immunol. 2018; 79(4):228-32.

36. Ma J, Wu D, Hu X, Li J, Cao M, Dong W. Associations between cytokine gene polymorphisms and susceptibility to helicobacter pylori infection and helicobacter pylori related gastric cancer, peptic ulcer disease: a metaanalysis. PLoS One. 2017;12(4):e0176463.

37. Ovcharenko I, Nobrega MA, Loots GG, Stubbs L. ECR Browser: a tool for visualizing and accessing data from comparisons of multiple vertebrate genomes. Nucleic Acids Res. 2004;32:W280-W6.

38. Kel-Margoulis OV, Kel AE, Reuter I, Deineko IV, Wingender E. TRANSCompel ${ }^{\circledR}$ : a database on composite regulatory elements in eukaryotic genes. Nucleic Acids Res. 2002;30(2):332-4.

39. Demeler B, Zhou GW. Neural network optimization for E. coli promoter prediction. Nucleic Acids Res. 1991;19(7):1593-9.

40. Liu R, States DJ. Consensus promoter identification in the human genome utilizing expressed gene markers and gene modeling. Genome Res. 2002; 12(3):462-9.

41. Jennes I, Zuntini M, Mees K, Palagani A, Pedrini E, De Cock G, et al. Identification and functional characterization of the human EXT1 promoter region. Gene. 2012;492(1):148-59.

42. Song H, Wang M, Wang Z, Liu J, Qi J, Zhang Q. Characterization of kiss2 and kissr2 genes and the regulation of kisspeptin on the HPG axis in Cynoglossus semilaevis. Fish Physiol Biochem. 2017;43(3):731-53. 
43. Võ Anh Khoa Đ, Ponsuksili S, Murani E, Wimmers K. Polymorphic sites in the 5'-region of the porcine C8A gene. Arch Anim Breeding. 2011;54:430-8.

44. Xin S, Wang X, Dai G, Zhang J, An T, Zou W, et al. Bioinformatics analysis of SNPs in IL-6 gene promoter of Jinghai yellow chickens. Genes. 2018;9:446.

45. ENCODE Project Consortium. A user's guide to the encyclopedia of DNA elements (ENCODE). PLoS Biol. 2011;9(4):e1001046.

46. Sloan CA, Chan ET, Davidson JM, Malladi VS, Strattan JS, Hitz BC, et al. ENCODE data at the ENCODE portal. Nucleic Acids Res. 2016;44(D1):D726D32.

47. ENCODE Project Consortium. An integrated encyclopedia of DNA elements in the human genome. Nature. 2012;489(7414):57-74.

48. Yang C, Bolotin E, Jiang T, Sladek FM, Martinez E. Prevalence of the initiator over the TATA box in human and yeast genes and identification of DNA motifs enriched in human TATA-less core promoters. Gene. 2007;389(1):5265.

49. Solovyev W, Shahmuradov IA, Salamov AA. Identification of promoter regions and regulatory sites. Methods Mol Biol. 2010;674:57-83.

50. Wang J, Hannenhalli S. A mammalian promoter model links cis elements to genetic networks. Biochem Biophys Res Commun. 2006;347(1):166-77.

51. Zhang G, Zhou B, Li S, Yue J, Yang H, Wen Y, et al. Allele-Specific Induction of IL-1 $\beta$ Expression by C/EBP $\beta$ and PU.1 Contributes to Increased Tuberculosis Susceptibility. PLOS Pathog. 2014;10(10):e1004426.

52. Lind $\mathrm{H}$, Haugen $\mathrm{A}$, Zienolddiny $\mathrm{S}$. Differential binding of proteins to the IL1B -31 T/C polymorphism in lung epithelial cells. Cytokine. 2007;38(1): $43-8$

53. El-Omar EM, Carrington M, Chow W-H, McColl KEL, Bream JH, Young HA, et al. Interleukin-1 polymorphisms associated with increased risk of gastric cancer. Nature. 2000;404(6776):398-402

54. Al-Moundhri MS, Al-Nabhani M, Al-Bahrani B, Burney IA, Al-Madhani A, Ganguly SS, et al. Interleukin-1 beta gene (IL-1B) and interleukin 1 receptor antagonist gene (IL-1RN) polymorphisms and gastric cancer risk in an Omani Arab population. Gastric Cancer. 2006:9(4):284-90.

55. Hartland S, Newton JL, Griffin SM, Donaldson PT. A functional polymorphism in the interleukin-1 receptor-1 gene is associated with increased risk of helicobacter pylori infection but not with gastric cancer. Dig Dis Sci. 2004;49(9):1545-50.

56. Zhao Y, Wang JW, Tanaka T, Hosono A, Ando R, Tokudome S, et al. Association between TNF-alpha and IL-1 beta genotypes vs helicobacter pylori infection in Indonesia. World J Gastroenterol. 2013;19(46):8758-63.

57. Drici Ael M, Moulessehoul S, Tifrit A, Diaf M, Turki DK, Bachir M, et al. Effect of IL-1beta and IL-1RN polymorphisms in carcinogenesis of the gastric mucosa in patients infected with helicobacter pylori in Algeria. Libyan J Med. 2016;11:31576.

58. Kumar S, Kumar A, Dixit VK. Evidences showing association of interleukin-1B polymorphisms with increased risk of gastric cancer in an Indian population. Biochem Biophys Res Commun. 2009;387(3):456-60.

59. Ruzzo A, Graziano F, Pizzagalli F, Santini D, Battistelli V, Panunzi S, et al. Interleukin $1 \mathrm{~B}$ gene (IL-1B) and interleukin 1 receptor antagonist gene (IL$1 \mathrm{RN}$ ) polymorphisms in helicobacter pylori-negative gastric cancer of intestinal and diffuse histotype. Ann Oncol. 2005;16(6):887-92.

60. Xue H, Lin B, Ni P, Xu H, Huang G. Interleukin-1B and interleukin-1 RN polymorphisms and gastric carcinoma risk: a meta-analysis. J Gastroentero Hepatol. 2010;25(10):1604-17.

61. Kimura R, Nishioka T, Soemantri A, Ishida T. Cis-acting effect of the IL1B C $-31 T$ polymorphism on IL-1 $\beta$ mRNA expression. Genes Immun. 2004;5(7): 572-5.

62. Santtila S, Savinainen K, Hurme M. Presence of the IL-1RA allele 2 (IL1RN*2) is associated with enhanced IL-1 beta production in vitro. Scand J Immunol. 1998;47(3):195-8.

63. Hwang I-R, Kodama T, Kikuchi S, Sakai K, Peterson LE, Graham DY, et al. Effect of interleukin 1 polymorphisms on gastric mucosal interleukin $1 \beta$ production in helicobacter pylori infection. Gastroenterology. 2002;123(6): 1793-803.

64. Kaijzel EL, Bayley JP, van Krugten MV, Smith L, van de Linde P, Bakker AM, et al. Allele-specific quantification of tumor necrosis factor a (TNF) transcription and the role of promoter polymorphisms in rheumatoid arthritis patients and healthy individuals. Genes Immun. 2001;2(3):135-44.

65. Harbage B, Dean AG. Distribution of Epi info software: an evaluation using the internet. Am J Prev Med. 1999;16(4):314-7.

66. Su Y, Yoon SS. Epi info - present and future. AMIA Annu Symp Proc. 2003; 2003:1023.
67. Idris AB, Ataelmanan AE, Eltaher SM, Idris EB, Osman Arbab BM, Ibn Idris A, et al. Independently Carriage of IL-1RN*2 Allele associated with increased risk of gastric cancer in the Sudanese Population. medRxiv. 2019:19013573. https://www.medrxiv.org/content/10.1101/19013573v1.

68. Carbone M, Maugeri TL, Gugliandolo C, La Camera E, Biondo C, Fera MT. Occurrence of helicobacter pylori DNA in the coastal environment of southern Italy (straits of Messina). J Appl Microbiol. 2005;98(3):768-74.

69. Idris $A B$, Hassan HG, Ali MAS, Eltaher SM, Idris LB, Altayb HN, et al. Molecular phylogenetic analysis of 165 rRNA sequences identified two lineages of helicobacter pylori strains detected from different regions in Sudan suggestive of differential evolution. Int J Microbiol. 2020;2020: 8825718 .

70. Furuta T, El-Omar EM, Xiao F, Shirai N, Takashima M, Sugimura H. Interleukin 1 beta polymorphisms increase risk of hypochlorhydria and atrophic gastritis and reduce risk of duodenal ulcer recurrence in Japan. Gastroenterology. 2002;123(1):92-105.

71. FinchTV. 1.4.0 ed. USA: Geospiza, Inc.; Seattle, 2012.

72. Altschul SF, Madden TL, Schäffer AA, Zhang J, Zhang Z, Miller W, Lipman DJ. Gapped BLAST and PSI-BLAST. A new generation of protein database search programmes. Nucleic Acids Res. 1997;25(17):3389-402.

73. Hall TA. BioEdit: a user-friendly biologicalsequence alignment editor and analysis programfor windows 95/98/NT. Nucl Acids Symp Ser. 1999;41:95-8.

74. Umarov R. Novel computational methods for promoter identification and analysis. Thuwal, Kingdom of Saudi Arabia: King Abdullah University of Science and Technology; 2020.

75. Knudsen S. Promoter2.0: for the recognition of Polll promoter sequences. Bioinformatics (Oxford, England). 1999;15(5):356-61.

76. Reese MG. Application of a time-delay neural network to promoter annotation in the Drosophila melanogaster genome. Comput Chem. 2001;26(1):51-6.

77. Wingender $\mathrm{E}$, Dietze $\mathrm{P}$, Karas $\mathrm{H}$, Knüppel R. TRANSFAC: a database on transcription factors and their DNA binding sites. Nucleic Acids Res. 1996; 24(1):238-41.

78. Solovyev V, Kosarev P, Seledsov I, Vorobyev D. Automatic annotation of eukaryotic genes, pseudogenes and promoters. Genome Biol. 2006;7 Suppl 1(Suppl 1):S10.1-12.

79. Ghosh D. A relational database of transcription factors. Nucleic Acids Res. 1990;18(7):1749-56.

80. Li L-C, Dahiya R. MethPrimer: designing primers for methylation PCRs. Bioinformatics (Oxford, England). 2002;18(11):1427-31.

81. Farré $D$, Roset $R$, Huerta M, Adsuara JE, Roselló L, Albà MM, et al. Identification of patterns in biological sequences at the ALGGEN server: PROMO and MALGEN. Nucleic Acids Res. 2003;31(13):3651-3.

82. Messeguer X, Escudero R, Farre D, Nunez O, Martinez J, Alba MM. PROMO: detection of known transcription regulatory elements using species-tailored searches. Bioinformatics (Oxford, England). 2002;18(2):333-4.

83. Grabe N. AliBaba2: context specific identification of transcription factor binding sites. In Silico Biol. 2002;2(1):S1-15.

84. Kel AE, Gößling E, Reuter I, Cheremushkin E, Kel-Margoulis OV, Wingender $\mathrm{E}$. MATCHTM: a tool for searching transcription factor binding sites in DNA sequences. Nucleic Acids Res. 2003;31(13):3576-9.

85. Fu Y, Weng Z. Improvement of TRANSFAC matrices using multiple local alignment of transcription factor binding site sequences. Genome Inform. 2005;16(1):68-72.

86. Lee T-Y, Chang W-C, Hsu J, Chang T-H, Shien D-M. GPMiner: An integrated system for mining combinatorial cis-regulatory elements in mammalian gene group. BMC Genomics. 2012;13 Suppl 1:S3.

87. Sandelin A, Alkema W, Engström P, Wasserman WW, Lenhard B. JASPAR: an open-access database for eukaryotic transcription factor binding profiles. Nucl Acids Res. 2004;32(suppl_1):D91-D4.

88. Bucher P. Weight matrix descriptions of four eukaryotic RNA polymerase II promoter elements derived from 502 unrelated promoter sequences. J Mol Biol. 1990;212(4):563-78

89. Tsunoda T, Takagi T. Estimating transcription factor bindability on DNA. Bioinformatics (Oxford, England). 1999;15(7-8):622-30.

90. Ghosh D. Object-oriented transcription factors database (ooTFD). Nucleic Acids Res. 2000;28(1):308-10.

91. Deyneko IV, Kel AE, Kel-Margoulis OV, Deineko EV, Wingender E, Weiss S. MatrixCatch - a novel tool for the recognition of composite regulatory elements in promoters. BMC Bioinformatics. 2013;14(1):241. 
92. Ovcharenko I, Loots GG, Giardine BM, Hou M, Ma J, Hardison RC, et al. Mulan: multiple-sequence local alignment and visualization for studying function and evolution. Genome Res. 2005;15(1):184-94.

93. Hamajima N, Saito T, Matsuo K, Kozaki K, Takahashi T, Tajima K. Polymerase chain reaction with confronting two-pair primers for polymorphism genotyping. Japanese J Cancer Res. 2000;91(9):865-8.

\section{Publisher's Note}

Springer Nature remains neutral with regard to jurisdictional claims in published maps and institutional affiliations.

Ready to submit your research? Choose BMC and benefit from:

- fast, convenient online submission

- thorough peer review by experienced researchers in your field

- rapid publication on acceptance

- support for research data, including large and complex data types

- gold Open Access which fosters wider collaboration and increased citations

- maximum visibility for your research: over $100 \mathrm{M}$ website views per year

At BMC, research is always in progress.

Learn more biomedcentral.com/submissions 